\title{
Can Sense of Coherence Indicate Resilience and Mitigate the Cycle of Violence in Parenting?
}

\author{
Izumi Sawada $^{*}{ }^{(\mathbb{B}}$, Reiko Kishi², Tomoko Maruyama $^{1}$ \\ ${ }^{1}$ Sapporo Medical University, School of Health Sciences, Sapporo, Hokkaido \\ ${ }^{2}$ Hokkaido University, Center for Environmental and Health Sciences, Sapporo, Hokkaido \\ Email: ^izumi@sapmed.ac.jp
}

How to cite this paper: Sawada, I., Kishi, R. and Maruyama, T. (2021) Can Sense of Coherence Indicate Resilience and Mitigate the Cycle of Violence in Parenting? Open Journal of Nursing, 11, 728-741. https://doi.org/10.4236/ojn.2021.119062

Received: August 9, 2021

Accepted: September 14, 2021

Published: September 17, 2021

Copyright $\odot 2021$ by author(s) and Scientific Research Publishing Inc. This work is licensed under the Creative Commons Attribution International License (CC BY 4.0).

http://creativecommons.org/licenses/by/4.0/

\begin{abstract}
Background: Harsh parenting practices during childhood have long-term negative effects on children's mental health. A focus of nursing care on women's resilience should be implemented because mothers who have experienced violence tend to be harsh parents. Aim: This study investigated the association between mothers' violent experiences and harsh parenting (HP) and examined the effects of a sense of coherence (SOC) on this association, assuming that SOC can be an indicator of resilience. Method: In this prospective cohort study of 487 mothers, data were collected on SOC and history of intimate partner violence (IPV) at 1 year after childbirth and HP of their child at 18 months after childbirth. Results: In the 277 responses analyzed by multiple logistic regression analysis, a strong SOC moderating the effect on HP was observed for current IPV and witnessing IPV in childhood, but not for experiencing childhood corporal punishment. Discussion: SOC is a useful indicator of resilience in female victims of violence and is effective in regulating stress spillover. However, its effects are weakened by the learned acquisition aspect of violence. Conclusion: In nursing, providing support to alleviate stress and relearn parenting based on an assessment of the mother's history of violence and SOC as the resilience indicator is important in curbing HP.
\end{abstract}

\section{Keywords}

Harsh Parenting, Sense of Coherence, Intimate Partner Violence, Prospective Studies

\section{Introduction}

The Japanese government enacted the Child Abuse Prevention Act in 2000. 
However, the number of cases handled by child guidance centers in Japan in 2019 increased 176 times (to 193,780 cases) since 1990. In particular, psychological abuse has increased from 9092 cases (21.3\%) in 2008 to 88,391 cases (55.3\%) in 2019 and witnessing intimate partner violence (IPV) accounts for most of these cases [1]. Furthermore, a survey on corporal punishment conducted by Save the Children Japan in 2017 showed that about $60 \%$ of parents approve of corporal punishment for disciplining their children and about $70 \%$ of families have used corporal punishment [2]. In 2020, the Child Abuse Prevention Act will be amended to prohibit corporal punishment for discipline and active measures to prevent corporal punishment will be required in the future.

Although distinguishing between abuse and corporal punishment as defined in research is difficult, the concept of "harsh parenting" encompasses physical abuse and corporal punishment as a continuum. Harsh parenting (HP) includes coercive parenting tactics ranging from mild corporal punishment to escalated physical abuse and cruelty [3]. HP is associated with child aggression [4] [5] [6], lower verbal skills [7], problem behaviors [7] [8] [9], and depression [10], which have long-term effects on children's mental health. By breaking the cycle of violence in parenting, we can contribute to the prevention of mental illness and the improvement of lifelong mental health.

\subsection{Mechanisms of HP and Theoretical Perspectives}

The mechanism of HP occurrence has been examined based on different theoretical perspectives focused on intergenerational transmission. Studies based on a social learning perspective suggest intergenerational continuities in angry and aggressive behaviors [11] [12]. The social information processing perspective implies a connection between acceptance and the use of physical disciplinary strategies, the propensity for disciplinary escalation, and the risk for abuse perpetration [13]. The association between positive evaluations of harsh discipline and parents' aggressive behavior toward their children has been shown to be universal [14]. These studies hypothesize that the intergenerational transmission of HP occurs through direct learning of parenting behaviors and the mediation of positive evaluations of HP. On the other hand, as for the mechanism by which partner aggression and IPV increase HP, in social learning, learned violence becomes a family norm [15], and in stress theory, partner aggression and IPV spill overstress to the mother [16] [17].

Thus, both learning and stress theories explain how childhood HP experiences and current IPV contribute to HP. Interestingly, studies based on social developmental models using prospective data have showed a continuum of HP across generations, simultaneously pointing out the existence of moderators that interfere with the continuum [18]. In this study, we focused on the sense of coherence (SOC) based on the salutogenic theory proposed by Antonovsky [19] and examined the moderating effect of SOC on the propagation of domestic violence. 


\subsection{SOC as a Moderating Factor with Experiences of Violence}

SOC refers to a person's ability to use existing and potential resources to combat stress and promote health. SOC is based on one's perception of manageability, meaning, and comprehensibility [20]. Regarding the association between SOC and violence, the combined experience of violence/abuse during adulthood and low SOC increase the odds ratio (OR) of common symptoms [21], whereas high SOC appears to act as a mediator of the experience of violence and stress reactions at workplace [22]. Studies focusing on the relationship between parenting and SOC have reported that mothers with higher SOC experience lower stress, even when their children have severe autism symptoms [23]. Furthermore, lower SOC is associated with higher use of corporal punishment among mothers of children with intellectual disabilities [24]. These studies indicate that SOC may modulate mothers' HP through their perceptions and coping styles toward stressful violent experiences. Thus, we believe it is reasonable to assume that SOC is an indicator of resilience in mothers with violent experiences and a moderator of the cycle of violence.

\subsection{Study Aim}

The purpose of this study was to investigate the association between a mother's experiences of violence and HP of children aged between 1 and 2 years (when HP has been reported to increase) [16] and to examine the effect of SOC in modifying this association.

\section{Methods}

\subsection{Participants}

The participants included mothers who attended a 4-month infant checkup at public health centers in Sapporo City, Hokkaido Prefecture, Japan between May 2001 and June 2001. The researcher personally handed out the baseline questionnaire to 1500 mothers (10\% of the annual births) at the health checkup site. Written and verbal information regarding the purpose and methods of the study was provided to the participants; they were informed that participation in the survey was voluntary and answering the questionnaire was considered as their consent to participate. This study was approved by the Sapporo Medical University Ethics Committee (Approval no. 21-2-4).

\subsection{Data Collection}

This research was part of a prospective cohort study. Data were collected in three phases by self-administrated questionnaires. A baseline questionnaire was given to participants at the 4-month infant checkup that included questions about demographic data, unwished-for birth, and child health status; in total, 487 (32.5\%) participants responded to the questionnaire. One year after childbirth, the second questionnaire was mailed to each participant that included questions 
about SOC, IPV experiences during the 1 year after childbirth, childhood experiences of severe corporal punishment by parents, and childhood experiences of witnessing physical violence between their parents. A third follow-up questionnaire was mailed to mothers 18 months after childbirth that focused on HP behaviors, life events, and satisfaction with the husbands' support. For each phase, reminders were sent to the participants twice.

\subsection{Measurement}

\subsubsection{HP Behaviors}

We referred to the child-rearing behaviors based on Watanabe's "Child Abuse and Risk Factors; A Survey in the Tokyo Metropolitan Area" [25], and the authors established a modified scale that included 14 items: Slapping the hand, slapping the head, spanking, ignoring or refusing, slapping the face, pinching, cursing, locking up, hitting with objects, kicking, throwing things, shaking, neglecting feeding, and covering the mouth with a hand. These 14 items were classified into mild, moderate, and severe levels, based on the seriousness (Table 1). Respondents were asked to choose a frequency based on five ranks from "never" to "every day" for each item in the past 6 months. Participants were placed in the HP group if they answered "every day" for the mild level, more than "a few times a week" for the moderate level, or more than "a few times before" for the severe level. The internal consistency of the scale was good $(\alpha=0.77)$.

Table 1. Frequencies of harsh parenting behaviors and the definitively harsh group $(n=277)$.

\begin{tabular}{|c|c|c|c|c|c|c|c|c|c|}
\hline & & \multicolumn{2}{|c|}{ Every day $\mathbf{n}(\%)$} & \multicolumn{2}{|c|}{ A few times a week } & \multicolumn{2}{|c|}{ A few times a month } & \multicolumn{2}{|c|}{ A few times before } \\
\hline \multirow{4}{*}{$\begin{array}{l}\text { Mildly harsh } \\
\text { parenting behaviors }\end{array}$} & Slapping the hands & 11 & $(4.0)$ & 50 & $(18.1)$ & 60 & $(21.7)$ & 102 & $(36.8)$ \\
\hline & Slapping the heads & 5 & $(1.8)$ & 25 & $(9.0)$ & 25 & $(9.0)$ & 105 & $(37.9)$ \\
\hline & Spanking & 6 & $(2.2)$ & 30 & $(10.8)$ & 44 & $(15.9)$ & 79 & $(28.5)$ \\
\hline & Ignoring & 3 & (1.1) & 25 & $(9.0)$ & 27 & (9.7) & 150 & $(54.2)$ \\
\hline \multirow{4}{*}{$\begin{array}{l}\text { Moderately harsh } \\
\text { parenting behaviors }\end{array}$} & Slapping the face & 3 & (1.1) & 4 & $(1.4)$ & 11 & $(4.0)$ & 43 & $(15.5)$ \\
\hline & Pinching & 2 & $(0.7)$ & 1 & $(0.4)$ & 7 & $(2.5)$ & 28 & $(10.1)$ \\
\hline & Cursing & 1 & $(0.4)$ & 10 & (3.6) & 16 & (5.8) & 51 & $(18.4)$ \\
\hline & Locking up & & & & & 2 & $(0.7)$ & 23 & $(8.3)$ \\
\hline \multirow{6}{*}{$\begin{array}{c}\text { Severely harsh } \\
\text { parenting behaviors }\end{array}$} & Hitting with an object & 1 & $(0.4)$ & 1 & $(0.4)$ & 2 & $(0.7)$ & 17 & $(6.1)$ \\
\hline & Kicking & & & 3 & $(1.1)$ & 2 & $(0.7)$ & 6 & $(2.2)$ \\
\hline & Throwing things & & & & & 2 & $(0.7)$ & 8 & $(2.9)$ \\
\hline & Shaking & & & & & 1 & $(0.4)$ & 17 & $(6.1)$ \\
\hline & Neglecting feeding & & & & & 1 & $(0.4)$ & 3 & $(1.1)$ \\
\hline & Covering the mouth & & & & & & & 18 & $(6.5)$ \\
\hline
\end{tabular}

The harsh parenting group included 69 (24.9\%) mothers (bolded in the table). 


\subsubsection{Experience of IPV}

Experience of IPV was measured using a modified instrument developed by the authors. The instrument consisted of 19 items, including eight types of psychosocial violence, eight types of physical violence, and three types of sexual violence. Respondents were asked to choose a frequency based on five ranks from "never" to "every day" for each item. Participants were placed in the IPV group if they answered "more than a few times a month" for a type of psychosocial violence or "more than a few times before" for a type of physical or sexual violence.

\subsubsection{Experience of Violence in Childhood}

Childhood experience of severe corporal punishment by parents and childhood experience of witnessing physical violence between parents was determined using the following questions. When you were 18 years old or younger, were you ever exposed to either of the following: 1) Severe corporal punishment by your parents? 2) Witnessed your father kick or beat your mother? Respondents were asked to choose a frequency based on five responses from "never" to "every day," and a mother was considered to have experienced childhood violence if she answered in the affirmative to either item.

\subsubsection{SOC Scale}

In this study, we used an abbreviated version of the SOC scale comprised 13 items, which showed good discriminating validity in Japan [26]. Respondents were asked to choose a number from one ("never") to seven ("very often") on each item. The scores were added together, giving a possible range of 13 - 91 . The distribution of scores was dichotomized at the lower one-third position. Those mothers who scored under that level were considered to have a weak SOC. Those who scored over that level were considered to have a moderate or strong SOC.

\subsection{Data Analysis}

Data were analyzed using multivariate logistic regression analysis. ORs were used to estimate the bivariate associations between childhood and adult experiences of violence and HP behaviors. To assess the potential confounding effects of the relationship between the experience of violence and HP, the variables for which statistical significance was suggested in chi-square analysis, were entered into three separate multivariate logistic regression models based on violent experience type. To clarify the effect modification of SOC on the relationship between the experience of violence and HP, the following groups were used: mothers with childhood experience of corporal punishment but with a strong or moderate SOC, mothers with no childhood experience of corporal punishment but with a weak SOC, and mothers with childhood experience of corporal punishment and a weak SOC. ORs were used to estimate relative risks. In the same manner, effect modification of witnessing physical IPV during childhood and the experience of IPV during 1 year after childbirth was examined. The Statistic- 
al Package for the Social Sciences (IBM, Armonk, NY, USA) was used for all statistical analyses. Statistical significance was determined at the $95 \%$ confidence interval (CI) level.

\section{Results}

Of the 487 mothers who agreed to participate in this study, 362 (74.3\%) responded at 1 year after childbirth and $355(72.9 \%)$ at 18 months after childbirth. The final analysis included 277 effectual respondents (56.9\%) who provided all responses to the questionnaires.

\subsection{Demographic Characteristics}

Demographic characteristics of the effectual respondents were compared with those of the non-effectual respondents using the chi-square test. The percentage of mothers aged $\geq 26$ was $87 \%$ in the effectual respondents group and $77.3 \%$ in the non-effectual respondents group $(\mathrm{p}=0.010)$. Of the effectual and non-effectual respondents, $36.9 \%$ and $48.1 \%$ mothers, respectively, did not graduate from high school ( $\mathrm{p}=0.015) ; 89.2 \%$ and $75.4 \%$, respectively, were housewives $(\mathrm{p}<0.001)$; and $10.5 \%$ and $16.9 \%$, respectively, were economically insecure $(p=0.042)$. All the above mentioned parameters were statistically significant.

\subsection{Defined Groups Based on HP, Experience of Violence, and SOC}

According to the definition described above, the HP group included 69 mothers (24.9\%) (shaded text in Table 1). In total, 69 mothers (24.9\%) experienced IPV, 93 mothers (33.6\%) experienced severe corporal punishment by their parents during childhood and 92 (33.2\%) mothers witnessed physical IPV between their parents during childhood (Table 2). The total SOC scores ranged from 17 to 89 , and the mean score was $63.2 \pm 12.6$. The weak SOC group included 86 mothers (31.4\%).

Table 2. Association between demographic and psychosocial variables and harsh parenting behaviors, presented as crude odds ratios and $95 \%$ confidence intervals.

\begin{tabular}{|c|c|c|c|c|}
\hline Variables & Number & Harsh group (\%) & Crude OR $(95 \% \mathrm{CI})$ & P-value \\
\hline \multicolumn{5}{|c|}{ Age } \\
\hline$>26$ years & 241 & 21.2 & 1 (reference) & \multirow{2}{*}{$0.001^{* *}$} \\
\hline$\leq 25$ years & 36 & 50.0 & $3.70(1.82-7.69)$ & \\
\hline \multicolumn{5}{|c|}{ Marital status } \\
\hline Married & 271 & 24.7 & 1 (reference) & \multirow{2}{*}{0.641} \\
\hline Not married & 6 & 33.3 & $1.52(0.27-8.50)$ & \\
\hline \multicolumn{5}{|c|}{ Employment status } \\
\hline Employed & 42 & 33.3 & 1 (reference) & \multirow{2}{*}{0.179} \\
\hline Unemployed & 235 & 23.4 & $0.61(0.30-1.24)$ & \\
\hline
\end{tabular}




\section{Continued}

\begin{tabular}{|c|c|c|c|c|}
\hline \multicolumn{5}{|c|}{ Educational level } \\
\hline$\leq$ High school & 102 & 27.7 & 1 (reference) & \multirow{2}{*}{0.062} \\
\hline >High school & 175 & 19.1 & $0.59(0.34-1.02)$ & \\
\hline \multicolumn{5}{|c|}{ Cohabitation (besides husband and children) } \\
\hline Cohabiting & 249 & 24.9 & 1 (reference) & \multirow{2}{*}{1.000} \\
\hline Not cohabiting & 28 & 25.0 & $1.01(0.41-2.48)$ & \\
\hline \multicolumn{5}{|c|}{ Number of children } \\
\hline $1-2$ & 255 & 23.9 & 1 (reference) & \multirow[b]{2}{*}{0.204} \\
\hline$\geq 3$ & 22 & 36.4 & $1.82(0.73-4.54)$ & \\
\hline \multicolumn{5}{|c|}{ Anxiety about cost of living } \\
\hline None or little & 248 & 23.8 & 1 (reference) & \multirow{2}{*}{0.255} \\
\hline Very much & 29 & 34.5 & $1.69(0.74-3.83)$ & \\
\hline \multicolumn{5}{|c|}{ Satisfaction with husband's support } \\
\hline None or so-so & 227 & 27.8 & 1 (reference) & \multirow{2}{*}{$0.019^{*}$} \\
\hline Very much & 50 & 12.0 & $0.35(0.14-0.88)$ & \\
\hline \multicolumn{5}{|c|}{ Planned parenthood } \\
\hline Yes & 249 & 23.3 & 1 (reference) & \multirow[b]{2}{*}{0.069} \\
\hline No & 28 & 39.3 & $2.10(0.94-4.76)$ & \\
\hline \multicolumn{5}{|c|}{ Life event } \\
\hline No & 154 & 19.5 & 1 (reference) & \multirow{2}{*}{$0.025^{*}$} \\
\hline Yes & 123 & 31.7 & $1.19(1.11-3.33)$ & \\
\hline
\end{tabular}

Childhood experience of severe corporal punishment

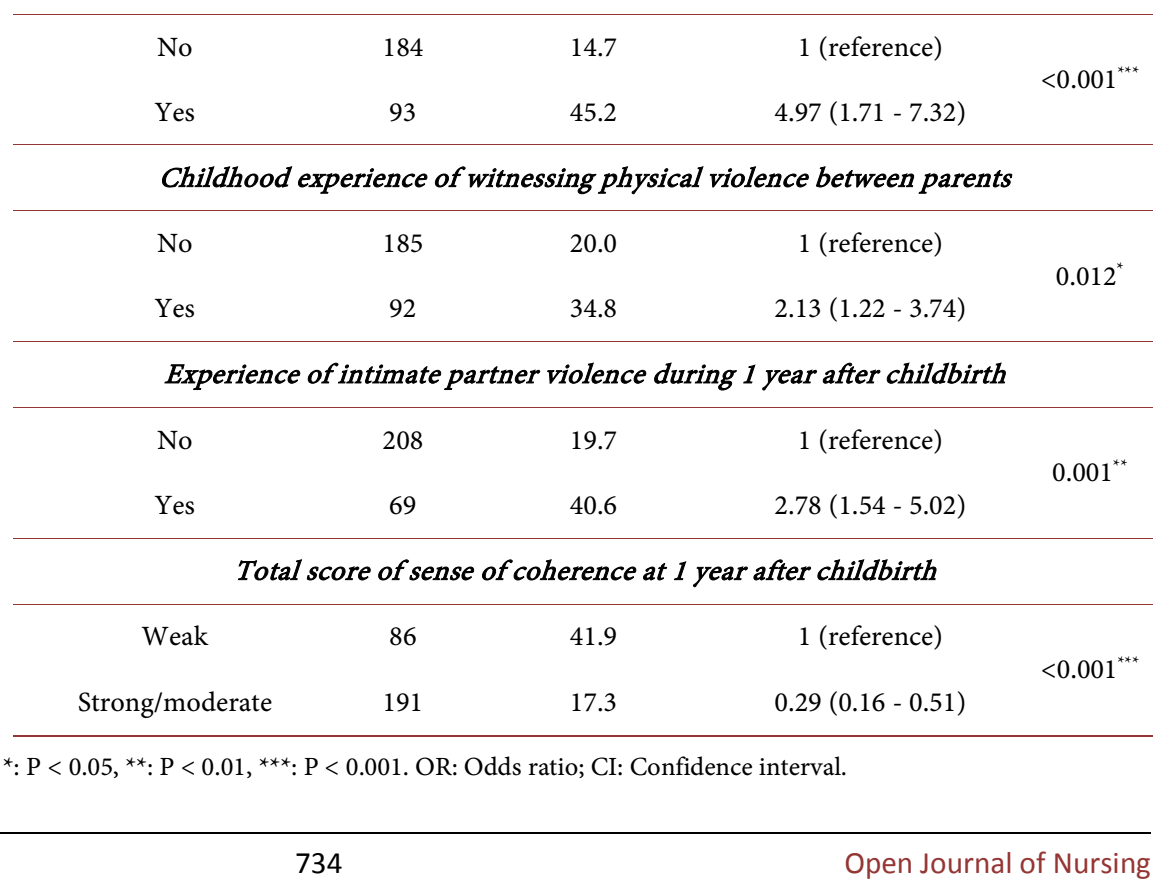




\subsection{Associated Variables of HP}

The associations between demographic and psychosocial variables and HP are presented as crude ORs with $95 \%$ confidence intervals in Table 2. Severe corporal punishment in childhood ( $\mathrm{OR}=4.97$; 95\% CI $1.71-7.32, \mathrm{p}<0.001)$, witnessed physical IPV between parents in childhood (OR $=2.13$; 95\% CI 1.22 $3.74, \mathrm{p}=0.012)$, and IPV during 1 year after childbirth $(\mathrm{OR}=2.78$; $95 \% \mathrm{CI} 1.54$ - 5.02, $\mathrm{p}=0.001)$ were associated with HP. Strong or moderate SOC had a significantly lower OR for HP than a weak SOC $(\mathrm{OR}=0.29 ; 95 \%$ CI $0.16-0.51, \mathrm{p}<$ 0.001). Young age, dissatisfaction with the husband's support, and life events were also significantly associated with HP.

\subsection{Multiple Logistic Regression Analyses}

A multiple logistic regression analysis was performed to examine the relationship between the experience of violence and HP, while controlling for age, satisfaction with husband's support, life events, and SOC (Table 3). In the three models of the different types of violence, the OR for the experience of severe corporal punishment $(\mathrm{OR}=3.85 ; 95 \% \mathrm{CI} 2.09-7.09, \mathrm{p}<0.001)$, age $(\mathrm{OR}=3.19$;

Table 3. Association between experience of violence and harsh parenting behaviors.

\begin{tabular}{|c|c|c|c|}
\hline Variables & Adjusted OR & $95 \% \mathrm{CI}$ & P-value \\
\hline \multicolumn{4}{|c|}{ Childhood experience of punishment } \\
\hline Childhood experience of punishment (yes/no) & 3.85 & $(2.09-7.09)$ & $<0.001^{* * *}$ \\
\hline Age (25/26 years old) & 3.19 & $(1.40-7.31)$ & $0.006^{* *}$ \\
\hline Life event (yes/no) & 1.40 & $(0.75-2.62)$ & 0.284 \\
\hline Husband' support (satisfaction/none) & 0.41 & $(0.15-1.09)$ & 0.074 \\
\hline SOC (strong/moderate/weak) & 0.45 & $(0.24-0.84)$ & $0.013^{*}$ \\
\hline \multicolumn{4}{|c|}{ Childhood experience of witnessing IPV } \\
\hline Childhood experience of witness IPV (yes/no) & 1.92 & $(1.04-3.52)$ & $0.036^{*}$ \\
\hline Age (25/26 years old) & 3.60 & $(1.63-7.92)$ & $0.001^{* *}$ \\
\hline Life event (yes/no) & 1.48 & $(0.82-2.70)$ & 0.196 \\
\hline Husband's support (satisfaction/none) & 0.37 & $(0.14-0.97)$ & $0.043^{*}$ \\
\hline SOC (strong/moderate/weak) & 0.41 & $(0.22-0.77)$ & $0.005^{* *}$ \\
\hline \multicolumn{4}{|c|}{ Experience of IPV during 1 year after childbirth } \\
\hline Experience of IPV during 1 year after childbirth (yes/no) & 2.05 & $(1.08-3.88)$ & $0.027^{*}$ \\
\hline Age $(25 / 26$ years old $)$ & 3.05 & $(1.38-6.73)$ & $0.006^{* *}$ \\
\hline Life event (yes/no) & 1.56 & $(0.86-2.84)$ & 0.146 \\
\hline Husband's support (satisfaction/none) & 0.40 & $(0.15-1.05)$ & 0.063 \\
\hline SOC (strong/moderate/weak) & 0.41 & $(0.22-0.75)$ & $0.004^{* *}$ \\
\hline
\end{tabular}

${ }^{*}: \mathrm{P}<0.05,{ }^{* *}: \mathrm{P}<0.01,{ }^{* * *}: \mathrm{P}<0.001 . \mathrm{OR}:$ Odds ratio; CI: Confidence interval; SOC: Sense of coherence; IPV: Intimate partner violence. 
$95 \%$ CI $1.40-7.31, \mathrm{p}=0.006)$ and for SOC $(\mathrm{OR}=0.45 ; 95 \%$ CI $0.24-0.84, \mathrm{p}=$ 0.013 ) remained statistically significant. The OR for childhood experience of witnessing physical violence $(\mathrm{OR}=1.92 ; 95 \% \mathrm{CI} 1.04-3.52, \mathrm{p}=0.036)$, for age $(\mathrm{OR}=3.60 ; 95 \%$, CI $1.63-7.92, \mathrm{p}=0.001)$, husband's support $(\mathrm{OR}=0.37 ; 95 \%$ CI0.14 - 0.97, $\mathrm{p}=0.043)$, and for SOC $(\mathrm{OR}=0.41 ; 95 \%$ CI $0.22-0.77, \mathrm{p}=0.005)$ remained significant. The OR for childhood experience of IPV during 1 year after childbirth $(\mathrm{OR}=2.05 ; 95 \%$ CI $1.08-3.88, \mathrm{p}=0.027)$, for age $(\mathrm{OR}=3.05 ; 95 \%$ CI $1.38-6.73, \mathrm{p}=0.006)$, and for SOC $(\mathrm{OR}=0.41 ; 95 \%$ CI $0.22-0.75, \mathrm{p}=0.004)$ remained statistically significant. In all multiple logistic models by type of violence, the statistical significance of each violence experience and SOC was maintained.

\subsection{Effect Modification of SOC on HP}

The effects of concurrent weak SOC on the association between experience of violence and HP were investigated (Table 4). Being exposed to corporal punishment during childhood together with a weak SOC increased the OR for HP (adjusted for age, life events, and the husband's support, OR = 8.67; 95\% CI 3.69 - 20.37, $\mathrm{p}<0.001)$. In the same manner, having witnessed physical IPV in childhood and having a weak SOC increased the OR for HP (OR $=4.43 ; 95 \% \mathrm{CI}$ $1.94-10.12, \mathrm{p}<0.001)$. For being exposed to IPV during 1 year after birth and

Table 4. Effects of the modification of the SOC on the association between experience of violence and harsh parenting behaviors.

\begin{tabular}{|c|c|c|c|}
\hline \multicolumn{2}{|l|}{ Adjusted OR } & $95 \% \mathrm{CI}$ & P-value \\
\hline \multicolumn{4}{|c|}{ Childhood experience of punishment } \\
\hline No childhood punishment/strong or moderate SOC & 1 & & \\
\hline Childhood punishment/strong or moderate SOC & 3.78 & $(1.70-8.39)$ & $0.001^{* *}$ \\
\hline No childhood punishment/weak SOC & 2.19 & $(0.91-5.30)$ & 0.081 \\
\hline Childhood punishment/weak SOC & 8.67 & $(3.69-20.37)$ & $<0.001^{* * *}$ \\
\hline \multicolumn{4}{|c|}{ Childhood experience of witnessing physical IPV } \\
\hline No childhood witnessing of IPV/strong or moderate SOC & 1 & & \\
\hline Childhood Witnessing of IPV/strong or moderate SOC & 2.19 & $(0.97-4.94)$ & 0.058 \\
\hline No childhood witnessing of IPV/weak SOC & 2.73 & $(1.23-6.04)$ & $0.013^{*}$ \\
\hline Childhood witnessing IPV/weak SOC & 4.43 & $(1.94-10.12)$ & $<0.001^{* * *}$ \\
\hline \multicolumn{4}{|c|}{ Experience of IPV during 1 year after birth } \\
\hline No experience of IPV/strong or moderate SOC & 1 & & \\
\hline Experience of IPV/strong or moderate SOC & 2.13 & $(0.90-5.06)$ & 0.087 \\
\hline No experience of IPV/weak SOC & 2.51 & $(1.18-5.43)$ & $0.017^{*}$ \\
\hline Experience of IPV/weak SOC & 4.93 & $(2.07-11.73)$ & $<0.001^{* * *}$ \\
\hline
\end{tabular}

${ }^{\star} \mathrm{P}<0.05 ;{ }^{* \star} \mathrm{P}<0.01 ;{ }^{* *} \mathrm{P}<0.001$. OR: Odds ratio; CI: Confidence interval; SOC: Sense of coherence; IPV: Intimate partner violence. 
having a weak SOC, the OR increased (OR = 4.93; 95\% CI $2.07-11.73$, p < 0.001). For mothers with a strong or moderate SOC, childhood witnessing of physical IPV and IPV during 1 year after birth lost significance. However, childhood experience of punishment remained statistically significant $(\mathrm{OR}=$ $3.78 ; 95 \%$ CI $1.70-8.39, \mathrm{p}=0.001)$.

\section{Discussion}

\subsection{Demographic Characteristics of Subjects}

Participants who completed follow-up had fewer high-risk groups for child abuse, such as poor, young, and poorly educated. In addition, the mean SOC of this study was 63, which is higher than the reported mean of 54 for the Japanese population aged 25 to 34 [26]. The inclusion of participants in the study may have been biased toward healthier mothers.

\subsection{Risk Factors for HP According to Mothers' Experiences of Violence}

Each of the three types of violent experiences increased the OR for HP, and parental HP was associated with childhood experiences of HP [11] [12] [13] [14] [18] [27] [28] and experiences of domestic violence [15] [16] [17], consistent with the results of previous studies. Furthermore, mothers witnessing physical violence between parents during childhood were associated with $\mathrm{HP}$, whereas mothers having a good relationship with a current partner were found to mitigate HP. Wood and Sommers [29] reported that girls who witnessed IPV in childhood may become aggressive in self-defense, or they may become aggressive to control a difficult situation. Support from husbands seemed to alleviate mothers' instinct for self-protection and parenting difficulties and reduce their aggression toward their children, but this needs to be further verified in future investigations.

\subsection{Effect Modification of SOC on the Association between Violent Experiences and HP}

The results of the present study showed that maternal SOC independently moderates the association between experiences of violence (i.e., witnessing corporal punishment and IPV as a child, and current IPV) and HP. These findings are similar to those of Kimura and Yamazaki [24], who found that SOC influences HP practices.

Furthermore, the way SOC mitigates the association between experiences of violence and HP depended on the type of violence experienced, with severe corporal punishment in childhood being significantly associated with HP, even if the SOC was "strong" or "moderate." We believe that these data indicate that mothers perceive corporal punishment in childhood as a correct method of discipline. SOC reflects a person's outlook on life, their ability to cope with stressful situations, their level of trust in identifying and benefiting from people and re- 
sources, and personal attitudes and behaviors [30]. Moreover, severe corporal punishment is possibly perceived as a useful resource for mothers. Russa and Rodriguez [13] reported that parents who resort to physical discipline strategies to address their children's misbehaviors and noncompliance may escalate to abusive levels in emotional and confrontational interactions. The highest OR of HP in childhood among the three violent experiences means positive perceptions of physical punishment and emotional escalation. Furthermore, SOC may not be able to moderate positive perceptions of physical punishment. The mechanism of the association between IPV and HP has been described as stress spillover [15] [16] [17]. Moreover, witnessing IPV is experienced by women as stress that can cause depression and aggression [29]. SOC, which is believed to take effect under high stress, may confer mitigating effects under these conditions.

This study showed that mothers who maintained high SOC despite various experiences of violence were able to use internal and external resources, control their own disadvantage and stress spillover, and choose healthy parenting with nonviolent strategies. Furthermore, the findings indicate that SOC can indicate resilience in mothers.

\subsection{Implications for Nursing Practice}

SOC is a useful measure of resilience and predictor of risky parenting behaviors and recovery. SOC indicates the ability to utilize resources and trust people, which may affect the acceptance and effect of support. In particular, mothers with low SOC may have difficulties in accepting health education and support programs. First, a trauma-informed approach that supports the mother's ability to trust others may be necessary, and screening for SOC may help in the selection of intervention strategies.

To break the cycle of violence, victims need to relearn safe parenting and accept support from the people around them. Opportunities are needed not only for mothers but also for their partners, families, schools, and community to learn about the negative health effects of HP and alternative positive parenting practices. A society that can effectively curb violence will enhance the moderating function of SOC, reduce HP among women who have been victims of violence, and contribute greatly to improving people's mental health.

\subsection{Limitations}

Although the data for this survey was collected in 2001, the results are not affected by time because the study purpose is not to reveal the distribution of abuse, but to reveal the mechanism of the abuse chain. However, the data were collected from a single city in Japan, and the collection rate was low. Therefore, the data are not representative of the general population, but rather represent the results of a relatively healthy population. In contrast, the number of $277 \mathrm{ef}-$ fectual responses is 10 times more than the number of explanatory variables (14 in this study), which is considered to be the standard sample size for logistic re- 
gression analysis [31]; hence, we believe that it is a sufficient sample size to obtain valid analysis results. Furthermore, the HP measurement tool is a prototype, and its reliability needs to be further verified.

\section{Acknowledgements}

This research was supported by JSPS KAKENHI, Grant Number 12672330. We would like to thank Rita Weingouht for the valuable advice and helpful suggestions. We also wish to thank Junichi Yoshino and Yasuko Yoshida for their assistance in collecting the material, and all the participants who faithfully answered the many questionnaires throughout the study.

\section{Conflicts of Interest}

The authors declare no conflicts of interest regarding the publication of this paper.

\section{References}

[1] Japanese Ministry of Health, Labor and Welfare (2019) Outline of the Act on the Partial Amendment to the Child Welfare Act, Etc. To Step up Efforts to Prevent Child Abuse (Act No. 46 of 2019).

https://www.mhlw.go.jp/english/policy/children/children-childrearing/dl/20191122 e.pdf.

[2] Save the Children, Japan (2018) Report on the Results of a Survey on Awareness and Actual Conditions of Corporal Punishment and Other Forms of Discipline for Children toward a Society Free of Punishment That Harms Children's Bodies and Minds. Save the Children Japan, Tokyo.

https://www.savechildren.or.jp/jpnem/jpn/pdf/php_report201802.pdf.

[3] Frías-Armenta, M. and McCloskey, L.A. (1998) Determinants of Harsh Parenting in Mexico. Journal of Abnormal Child Psychology, 26, 129-139.

https://doi.org/10.1023/A:1022621922331

[4] Chang, L., Schwartz, D., Dodge, K.A. and McBride-Chang, C. (2003) Harsh Parenting in Relation to Child Emotion Regulation and Aggression. Journal of Family Psychology, 17, 598-606. https://doi.apa.org/doi/10.1037/0893-3200.17.4.598

[5] Lansford, J.E., Malone, P.S., Dodge, K.A., Chang, L., Chaudhary, N., Tapanya, S., Oburu, P. and Deater-Deckard, K. (2010) Children's Perceptions of Maternal Hostility as a Mediator of the Link between Discipline and Children's Adjustment in Four Countries. International Journal of Behavioural Development, 34, 452-461. https://doi.org/10.1177\%2F0165025409354933

[6] Wang, J. and Wang, M. (2019) Harsh Parenting and Children's Peer Relationships: Testing the Indirect Effect of Child Overt Aggression as Moderated by Child Impulsivity. School Psychology International, 40, 366-380.

https://doi.org/10.1177\%2F0143034319844304

[7] Berthelon, M., Contreras, D., Kruger, D. and Palma, M.I. (2020) Harsh Parenting during Early Childhood and Child Development. Economics and Human Biology, 36, Article No. 100831. https://doi.org/10.1016/j.ehb.2019.100831

[8] Mendez, M., Durtschi, J., Neppl, T.K. and Stith, S.M. (2016) Corporal Punishment and Externalizing Behaviors in Toddlers: The Moderating Role of Positive and Harsh Parenting. Journal of Family Psychology, 30, 887-895. 
https://doi.apa.org/doi/10.1037/fam0000187

[9] Kingsbury, M., Sucha, E., Manion, I., Gilman, S.E. and Colman, I. (2020) Adolescent Mental Health Following Exposure to Positive and Harsh Parenting in Childhood. Canadian Journal of Psychiatry, 65, 392-400.

https://doi.org/10.1177\%2F0706743719889551

[10] Tang, A.-M., Deng, X.-L., Du, X.-X. and Wang, M.-Z. (2018) Harsh Parenting and Adolescent Depression: Mediation by Negative Self-Cognition and Moderation by Peer Acceptance. School Psychology International, 39, 22-37. https://doi.org/10.1177\%2F0143034317709066

[11] Simons, R.L., Whitbeck, L.B., Conger, R.D. and Wu, C.-I. (1991) Intergenerational Transmission of Harsh Parenting. Developmental Psychology, 27, 159-171. https://doi.apa.org/doi/10.1037/0012-1649.27.1.159

[12] Conger, R.D., Neppl, T., Kim, K.J. and Scaramella, L. (2003) Angry and Aggressive Behavior across Three Generations: A Prospective, Longitudinal Study of Parents and Children. Journal of Abnormal Child Psychology, 31, 143-160. https://doi.org/10.1023/A:1022570107457

[13] Russa, M.B. and Rodriguez, C.M. (2010) Physical Discipline, Escalation, and Child Abuse Potential: Psychometric Evidence for the Analog Parenting Task. Aggressive Behavior, 36, 251-260. https://doi.org/10.1002/ab.20345

[14] Lansford, J.E., Woodlief, D., Malone, P.S., Oburu, P., Pastorelli, C., Skinner, A.T., Sorbring, E., Tapanya, S., Tirado, L.M., Zelli, A., Al-Hassan, S.M., Alampay, L.P., Bacchini, D., Bombi, A.S., Bornstein, M.H., Chang, L., Deater-Deckard, K., Di Giunta, L. and Dodge, K.A. (2014) A Longitudinal Examination of Mothers' and Fathers' Social Information Processing Biases and Harsh Discipline in Nine Countries. Development and Psychopathology, 26, 561-573.

https://doi.org/10.1017/S0954579414000236

[15] Graham, A.M., Kim, H.K. and Fisher, P.A. (2012) Partner Aggression in High-Risk Families from Birth to Age 3 Years: Associations with Harsh Parenting and Child Maladjustment. Journal of Family Psychology, 26, 105-114. https://doi.apa.org/doi/10.1037/a0026722

[16] Kim, H.K., Pears, K.C., Fisher, P.A., Connelly, C.D. and Landsverk, J.A. (2010) Trajectories of Maternal Harsh Parenting in the First 3 Years of Life. Child Abuse and Neglect, 34, 897-906. https://doi.org/10.1016/j.chiabu.2010.06.002

[17] Grasso, D.J., Henry, D., Kestler, J., Nieto, R., Wakschlag, L.S. and Briggs-Gowan, M.J. (2016) Harsh Parenting as a Potential Mediator of the Association between Intimate Partner Violence and Child Disruptive Behavior in Families with Young Children. Journal of Interpersonal Violence, 31, 2102-2126. https://doi.org/10.1177\%2F0886260515572472

[18] Bailey, J.A., Hill, K.G., Oesterle, S. and Hawkins, J.D. (2009) Parenting Practices and Problem Behavior across Three Generations: Monitoring, Harsh Discipline, and Drug Use in the Intergenerational Transmission of Externalizing Behavior. Developmental Psychology, 45, 1214-1226. https://doi.apa.org/doi/10.1037/a0016129

[19] Antonovsky, A. (1987) Unraveling the Mystery of Health: How People Manage Stress and Stay Well. Jossey-Bass, San Francisco.

[20] Shorey, S. and Ng, E.D. (2020) Application of the Salutogenic Theory in the Perinatal Period: A Systematic Mixed Studies Review. International Journal of Nursing Studies, 101, Article ID: 103398. https://doi.org/10.1016/j.ijnurstu.2019.103398

[21] Krantz, G. and Ostergren, P.O. (2000) The Association between Violence Victimisation and Common Symptoms in Swedish Women. Journal of Epidemiology and 
Community Health, 54, 815-821. https://doi.org/10.1136/jech.54.11.815

[22] Hogh, A. and Mikkelsen, E.G. (2005) Is Sense of Coherence a Mediator or Moderator of Relationships between Violence at Work and Stress Reactions? Scandinavian Journal of Psychology, 46, 429-437. https://doi.org/10.1111/j.1467-9450.2005.00474.x

[23] Mak, W.W.S., Ho, A.H.Y. and Law, R.W. (2007) Sense of Coherence, Parenting Attitudes and Stress among Mothers of Children with Autism in Hong Kong. Journal of Applied Research in Intellectual Disabilities, 20, 157-167. https://doi.org/10.1111/j.1468-3148.2006.00315.x

[24] Kimura, M. and Yamazaki, Y. (2016) Physical Punishment, Mental Health and Sense of Coherence among Parents of Children with Intellectual Disability in Japan. Journal of Applied Research in Intellectual Disabilities, 29, 455-467. https://doi.org/10.1111/jar.12198

[25] Watanabe, U., Kayama, M., Sagami, A., Senoo, E., Ohara, M. and Tokunaga, M. (2002) Child Abuse and Risk Factors: A Survey in Tokyo Metropolitan A. Japanese Society for Social Psychiatry, 10, 239-246.

[26] Togari, T. and Yamazaki, Y. (2005) Examination of the Reliability and Factor Validity of 13-Item Five Point Version Sense of Coherence Scale. Japanese Journal of Health \& Human Ecology, 71, 168-182.

[27] Conger, R.D., Schofield, T.J. and Neppl, T.K. (2012) Intergenerational Continuity and Discontinuity in Harsh Parenting. Parenting, 12, 222-231.

https://doi.org/10.1080/15295192.2012.683360

[28] Conger, R.D., Schofield, T.J., Neppl, T.K. and Merrick, M.T. (2013) Disrupting Intergenerational Continuity in Harsh and Abusive Parenting: The Importance of a Nurturing Relationship with a Romantic Partner. Journal of Adolescent Health, 53, S11-S17. https://doi.org/10.1016/j.jadohealth.2013.03.014

[29] Wood, S.L. and Sommers, M.S. (2011) Consequences of Intimate Partner Violence on Child Witnesses: A Systematic Review of the Literature. Journal of Child and Adolescent Psychiatric Nursing, 24, 223-236. https://doi.org/10.1111/j.1744-6171.2011.00302.x

[30] Eriksson, M. (2017) The Sense of Coherence in the Salutogenic Model of Health. In: Mittelmark, M.B., Sagy, S., Eriksson, M., Bauer, G.F., Pelikan, J.M., Lindström, B. and Espnes, G.A., Eds., The Handbook of Salutogenesis, Springer, Cham, 91-96. https://doi.org/10.1007/978-3-319-04600-6_11

[31] Peduzzi, P., Concato, J., Kemper, E., Holford, T.R. and Feinstein, A.R. (1996) A Simulation Study of the Number of Events Per Variable in Logistic Regression Analysis. Journal of Clinical Epidemiology, 49, 1373-1379.

https://doi.org/10.1016/S0895-4356(96)00236-3 